\title{
Building Research Skills: Course-Integrated Training Methods
}

\author{
Adriana Popescu ${ }^{1}$ and Radu Popescu, A.M.ASCE ${ }^{2}$
}

\begin{abstract}
An enriched syllabus has been experimentally introduced to undergraduate level students enrolled in a geotechnical engineering course. Two research assignments have been integrated in the course, which require students to find information on a geotechnical engineering topic using both print and electronic resources available at the university library and on the Internet. Aiming to foster the development of technical information literacy and communication skills, the students are required to prepare a report based on a specific set of guidelines, followed by oral presentations of the topics researched. Between the two assignments, a lecture on the subject of identifying and using information resources for geotechnical engineering is included in the syllabus. Preliminary results of the study are presented along with directions for designing and implementing an enriched curriculum for geotechnical engineering courses.
\end{abstract}

\section{Introduction}

The latest information technology developments, the Internet expansion, and the explosion of information now available on the World Wide Web (WWW) have radically changed the current educational system. In recent years we see less teachers carrying the distinctive mark, chalk dust around the coat sleeves, as modern technologies infiltrate the classrooms: first, the overhead projector, then the LCD projector and the PC, to the interactive boards and multimedia classrooms. More and more students substitute the notebooks with laptops, while institutions of higher education make every effort to ensure that classrooms provide enough LAN connections for all computer users. More communication and information diffusion channels are added to those already existent, bringing a new challenge in the spotlight: dealing with and surviving the information overload.

The consequences and implications of the technological developments cannot be ignored. They should be taken into consideration and addressed by educational systems and programs from all over the world. Being able to access, interpret, and evaluate relevant technical information in a timely and effective manner has become a commodity for all engineers. Effective oral and written communication and information literacy are highly desirable skills in today's employment market, but they are very little or not at all acquired through the traditional engineering curriculum. Like most engineering disciplines, geotechnical engineering is dynamic and is continuously adding to its body of knowledge,

${ }^{1}$ Librarian, Plasma Physics Library, Princeton Univ., Princeton, NJ 08544. E-mail: popescua@princeton.edu

${ }^{2}$ Associate Professor, Faculty of Engineering and Applied Science, Memorial Univ. of Newfoundland, St. John's, NL A1B 3X5, Canada. E-mail: radu@engr.mun.ca making it increasingly difficult for practicing engineers to keep up with the latest developments in the field. The young graduates of engineering programs begin their careers in work environments that require highly specialized competencies and a broad understanding of the discipline.

In order to keep up with the technological revolution, geotechnical engineering educators must be prepared to broaden their pedagogical role beyond passing on theoretical and practical knowledge to the students. When preparing engineers for this century, the educators must consider the increased significance of their responsibility to also teach and educate students to become efficient and effective information seekers and users.

\section{Teaching Roles}

The reality of the technological revolution in information and communication demands changing, adjusting, and enriching the traditional role of the educator, especially the engineering discipline educator. Information technology offers a wealth of opportunities to education: enhancing student learning, fostering collaboration, introducing new models of dissemination, distribution and publishing, and allowing the instruction process to take place in new settings, either remote or virtual.

While the world in which engineering is practiced has changed and continues to change, the engineering curricula tend to go unchanged for decades. At the same time, the engineering student population is also changing, with students from a broad age group and various backgrounds, entering the engineering profession. Fresh graduates of engineering programs entering the workforce are evaluated today not only based on their overall course ratings; more and more employers are looking for demonstrated computer skills, information literacy skills (defined as the ability to recognize information needs and identify, evaluate, and use information effectively); and critical and analytical thinking skills. Workplace processes such as environmental scanning, information management, and research and development are now the standard, therefore a new set of skills is necessary and the engineering educational programs must accommodate and facilitate the development and fostering of the modern engineer skill set. 
The National Science Foundation Workshop on Information Technology and Undergraduate Science, Mathematics, Engineering, and Technology Education held in 1996 acknowledged the paradigm shifts in undergraduate education, emphasizing the changing roles of the faculty. One of the concerns expressed at the time of the workshop was the fact that "access and data are for all intents and purposes commodity items; the proliferation of WWW sites speaks clearly on this point. Information (data organized and made accessible in a value-added way), however, is not a commodity, and dissemination mechanisms should reflect this distinction" (Zia and Mulder 1996). It is time that we move from recognizing the fact that educators must take responsibility for preparing young engineers for tomorrow's job market, to actual implementation of the steps necessary to accomplish this goal. It is the scope of this work to demonstrate that with the help and expertise of the professional librarian, the engineering educator can successfully accomplish this goal.

\section{Current Practices}

\section{Overview}

Library instruction is by no means a new concept; it has been traced back to 1820 , when a librarian was teaching students at Harvard College (Hernon 1982). In the late 1800s, separate courses for library instruction were implemented in colleges. However, by the end of the nineteenth century, interest in library instruction declined, only to be revived in the early 1900s, with the growth in the number of academic libraries (Tiefel 1995). Although at that time the efforts of librarians did not establish any formal programs of library instruction, their principles of educating students to be independent learners are still alive and valid today. The focus of the instruction activities has been also shifting, from teaching the use of materials for research and teaching, to how to access those materials. After the second world war, library collections grew rapidly. The rise in scientific research and consequently in scientific literature required new techniques of organization and information retrieval, a fact which brought in focus the need for better instruction in the field of information access (Edelman 1996). The automation of technical services in the 1950s overshadowed library instruction activities for a while, but the rise of specialization in education and the growing complexity of the library system lead to the rise of a new concept: curriculum integrated instruction programs.

Competence in the use of the library is one of the liberal arts. It deserves recognition and acceptance as such in the college curriculum. It is furthermore, a complex of knowledge, skills, and attitudes not to be acquired in any one course but functionally related to the content of many. It should, therefore, be integrated into the curriculum. But it cannot be so integrated until the faculty as a whole is ready to recognize the validity of its claim and implement this recognition through regularly established procedures of curriculum development (Knapp 1956).

While liberal arts educational programs have long ago accepted Knapp's recommendations and adopted the curriculum integrated library instruction system, the engineering educational programs have been slow in responding to this challenge.

It is encouraging to see however, that in the past decade there have been more and more reports of engineering education programs paying attention to this aspect of student education. Librarians and the faculty of the School of Engineering at University of
Pittsburgh recognized library research as being a basic engineering skill and worked together to introduce a program for developing library research skills and general information literacy early in a student's career (Thomes et al. 1997). At Purdue University, librarians and faculty share the responsibility for instruction in the design projects, which are semester-long courses in the civil engineering curriculum. While civil engineering faculty give lectures on various technical aspects relevant to each project, the librarians make presentations on information sources available and research skills (Erdmann 1991). With the proliferation of information on the WWW, librarians have shown a growing interest in teaching critical thinking skills, so that library users can effectively recognize and select the best information for their needs. The faculty from the Department of Manufacturing Engineering at Miami University in Oxford, Ohio, recognized the fact that more and more students use the WWW to acquire information, rather than the library resources, without applying any critical analysis of the information gathered. To address this shortfall, the department has introduced, since 1998, introductory sessions on WWW search strategies and results evaluation, and searching the library resources as part of the senior project course (Stenger 1998).

Time and social changes have influenced and shaped not only the evolution of library instruction ideology, but also its methods. Teaching methods, based on behavioral theories, where the subject seen as an empty vessel can be filled with knowledge, have emerged and eventually been given up. Cognitive theories, on the other hand, have provided the foundation for some of the most successful methods currently used in library instruction. Active participation in the learning process has proved to be the most efficient and desirable feature of instruction programs (Varner et al. 1996).

\section{Geotechnical Engineering Education at Memorial University of Newfoundland}

Geotechnical engineering (GE) is taught at Memorial University of Newfoundland (MUN) as part of the civil engineering curriculum. There are two GE courses offered to students in Terms 5 and 6. Like most engineering class assignments, the GE assignments are very structured and precisely defined. The students usually follow the steps outlined in the assignment and perform the calculations required. Like most technical training, the aim of the class assignments is to transmit information and to develop basic engineering skills, through drill-and-practice learning experiences of sequenced components. These assignments are far from the reality of the open-ended problems that engineers often encounter and must solve.

\section{Enriched GE Curriculum}

\section{Building Research Skills}

To address the limitations of the traditional GE curriculum, the second course (foundation engineering) taught in the Fall 1999 semester to Term 6 students, included two new research assignments in addition to regular engineering projects. The class was divided in groups of four students each. The cognitive learning theory shows that the education process should foster students' natural inclination to learn by engaging in activities that will interest them and will stimulate learning (Piaget 1970). The research assignments were designed to stimulate students' interest 
in information retrieval and evaluation and were addressing topics related to GE. In order to successfully complete the assignments, the students had to actively engage in research activities by using the university library and WWW resources and to demonstrate a satisfactory level of technical communication and writing skills.

The assignments are outlined in the Appendix. The first project, assigned at the beginning of the term when the students had little experience with theoretical and practical aspects of geotechnical engineering, was focusing mostly on biographical aspects of famous geotechnical engineers. The students' role was to retrieve, select, and present relevant data. A series of professional aspects were introduced in the second assignment, dealing with case histories. Here, in addition to retrieving and selecting information, the students were requested to identify the geotechnical problems and discuss one of the solutions reported in the literature.

Three tasks related to the research process were assigned for both projects: (1) detailed description of the research process, (2) list of sources searched and used, and (3) proper referencing. After evaluating the reports produced at the end of the first research assignment, it was clear that the students needed instruction and guidance in using the library resources available from the university library, and in report writing and presentation skills. Some of the problems were (1) no statement was made in any of the reports regarding the research process; (2) the main source of information accessed by the students was the WWW, while library resources were scarcely used, if at all; and (3) the sources of information were not properly referred in any of the reports.

\section{Course-Integrated Library Instruction}

A 1-h library instruction session was deemed necessary and provided prior to the second assignment. This session covered how to access print and on-line GE resources available from the university library, search strategies for searching on-line databases, and relevant WWW resources for GE.

The students were asked for feedback on the effectiveness and relevance of the instruction session, as well as on previous library training, through a questionnaire administered at the end of the instruction session. About $80 \%$ of respondents indicated that they had one introductory library orientation session, as part of the general introduction to the university and its services, while $20 \%$ did not mention such a session. The survey results showed that the skills demonstrated in the early orientation session have not been formally required in any subsequent assignment/project. Regarding the instruction session offered in Term 6, 90\% of respondents mentioned that this session was beneficial, and $60 \%$ indicated that this was the first time they learned about searching techniques for journal/conference papers.

Following the subject-specific instruction session, a second research assignment was given to the students. The reports resulting from the second GE research assignment for the Term 6 students showed an improved standard of quality: (1) the research process was described in detail, (2) the sources of information were listed in all reports, and (3) all reports indicated from 10 to 15 references, however none of the groups complied with the required style guide. The concepts and skills presented during the instruction session have been used and applied by the majority of the students. For example, while no reference to research process and sources of information were found in any of the first research assignment reports, those aspects were described in detail in the second assignment, with grades for this topic ranging from 4.0 to 4.5 on a 1 to 5 scale.

\section{Conclusions}

The quality of the research assignment reports showed that a onetime general introduction to library research skills early at the beginning of the engineering program is neither sufficient nor effective. Libraries are dynamic entities; more resources are added to the current collection and the format of the resources is changing and adapting to the latest technological developments. Unless the students are challenged in their program of studies to continuously use these resources, they will fall out of touch with the resources offered by the university library, and turn indiscriminately towards the WWW as the only information resource, while still lacking the necessary critical analysis skills needed to bring out the value from the WWW.

Based on the results reported in this work, the GE curriculum at MUN has been permanently modified. Two different assignments involving library and Internet research have been included, one in Term 5 and one in Term 6. An instruction session is provided in Term 5 in conjunction with the first assignment. It covers the library research process and resources available for GE, WWW resources for GE, and writing styles for technical reports. To reinforce the skills taught in Term 5, another research assignment, on a different topic, is required in Term 6.

The GE faculty at MUN will continue to explore the use of the WWW technologies in teaching and will actively promote the importance of preparing future engineers for the social and technological realities facing the young graduates. An on-line module for instruction in using the library resources and searching and evaluating Internet resources is considered for implementation in a GE Web site maintained by the teaching faculty (http:// geosim.engr.mun.ca/inforres.htm) in order to supplement the curriculum-integrated instruction sessions.

As this project had successfully proved, close collaboration between the faculty and the library professional is the key to designing and implementing a program where the expertise in providing access to scientific and technical information complements and coordinates with the technical engineering expertise. Same as the teaching faculty, librarians are educators and their expertise should be fully taken advantage of for the benefit of the students and future geotechnical engineers.

\section{Appendix: Assignments}

\section{Research Assignment 1-Prominent Personalities in Geotechnical Engineering}

Each group (4 students) will select one scholar of the list below and write a short report describing his life, professional achievements and major contributions to the field of geotechnical engineering. Your report will include the following:

1. Short biography, pointing out to professional events $(0.5-1$ page);

2. Major contributions to the field of geotechnical engineering and areas of applicability (1-2 pages);

3. Major publications-if possible include some (famous) quotes (1-2 pages);

4. Anecdotal events (optional);

5. Your research process, as detailed below; and

6. List of your references for this report.

Some library and Internet research is required. One of the objectives of this assignment is assessing your ability to access, interpret, and evaluate relevant information in a timely and effective manner. Therefore, you are required to clearly state in your 
report your sources of information. These sources should be properly referred, and presented in the reference list. Use the recommended style of the Canadian Geotechnical Journal as outlined at 〈http://www.nrc.ca/cgi-bin/cisti/journals/rp/ rp2_prog_e?cgj_instruct_e.html $\rangle$. When citing Internet resources, use the guidelines available at 〈http://www.apastyle.org/ elecref.html $\rangle$. In the text of the report you are expected to comment on how you found, accessed, and selected those sources of information. The report will be printed using $12 \mathrm{pt}$ font and 1.5 line spacing. The page numbers suggested for some of the sections are only indicative.

List of some famous geotechnical engineers, in alphabetical order (Karl Terzaghi has been omitted on purpose):

- L. Bjerrum

- A. Casagrande

- J. I. Clark

- G. W. Clough

- C. A. Coulomb

- W. Fellenius

- W. D. L. Finn

- D. G. Fredlund

- R. M. Hardy

- R. D. Holtz

- K. Ishihara

- M. Jamiolkowski

- S. Leroueil

- G. G. Meyerhof

- J. K. Mitchell

- R. B. Peck

- W. J. M. Rankine

- R. K. Rowe

- H. B. Seed

- A. W. Skempton

\section{Research Assignment 2-Case Histories in Geotechnical Engineering}

Library and Internet research is required. One of the objectives of this assignment is to enhance your ability to access, interpret, and evaluate relevant information in a timely and effective manner.

Each group (4 students) will select one case denoting a geotechnical failure from the list below and write a short report describing the event, and the conditions under which the event took place. Make sure you identify the geotechnical problem(s) for the case you investigate and present one solution you found in the literature. Your report will include the following:

1. General description of the event (1 page);

2. Identification of the geotechnical problem(s) involved (1 page);

3. Discussion of one solution reported in the literature (1 page);

4. Describe in detail the research process you applied for this assignment: describe your research strategy, list all resources searched, print and electronic, report any interactions you had with librarians, any problems or difficulties encountered, etc. (2 pages);
5. Reference list - use the recommended style of the Canadian Geotechnical Journal as outlined at $\langle$ http://www.nrc.ca/cgibin/cisti/journals/rp/rp2_prog_e?cgj_instruct_e.html . When citing Internet resources, use the guidelines available at $\langle$ http://www.apastyle.org/elecref.html .

The report will be printed using 12 pt font and 1.5 line spacing.

The page numbers suggested for the sections are only indicative.

The list of proposed case histories includes

- Pisa Tower;

- Lower San Fernando Dam failure;

- Carsington Dam failure;

- Kettleman Hills Waste Landfill slope failure;

- Desert View Drive Embankment failure;

- La Conchita slide;

- Landslide Dam on the Saddle River (Alberta);

- Transcona Grain Elevator failure;

- Buffalo Creek Disaster, West Virginia; and

- Vaiont Dam Landslide, Italy.

\section{Acknowledgments}

The second writer was partially supported by Natural Sciences and Engineering Research Council (NSERC), Grant No. RG203795-98. This support is gratefully acknowledged.

\section{References}

Edelman, H. (1996). “The American University library: Embattled by economics and technology." Logos, 7(1), 102-105.

Erdmann, C. A. (1991). "Design projects: Librarians and faculty working together." Frontiers in Education Conf., IEEE, New York, 313-314.

Hernon, P. (1982). "Instruction in the use of academic libraries: A preliminary study of the early years as based on selective extant materials." Journal of Library History, 17, 16-38.

Knapp, P. (1956). "A suggestive program of college instruction in the use of the library." Library Q., July, 230.

Piaget, J. (1970). Science of education and the psychology of the child, Orion, New York.

Stenger, J. B. (1998). "Improving World Wide Web and library research." Frontiers in Education Conf., IEEE, New York, 80-83.

Thomes, K., Cornell, E., and Gottfried, B. (1997). "Teaching freshmen to write technical reports and to navigate the library: A win-win situation." Frontiers in Education Conf., IEEE, New York, 1557-1563.

Tiefel, V. (1995). "Library user education: Examining its past, projecting its future." Library Trends, 44(2), 318-338.

Varner, C. H., Schwartz, V. M., and George, J. (1996). "Library instruction and technology in a general education 'gateway' course: The student's view." J. Acad. Librarianship, 22, 355-359.

Zia, L. L., and Mulder, M. C. (1996). "NSF workshop on information technology and undergraduate science, mathematics, engineering, and technology education: Challenges and opportunities." IEEE Trans. Educ. 39(3), 452-454. 